\title{
Isolation and characterization of a Rhodotorula glutinis mutant defective in glucose transport
}

\author{
BirgitTa MilbradT* and Milan HöFer \\ Botanisches Institut der Universität Bonn, Kirschallee 1, 5300 Bonn, FRG
}

(Received 9 April 1990; revised 18 June 1990; accepted 29 June 1990)

\begin{abstract}
Mutants of the obligatorily aerobic yeast Rhodotorula glutinis, obtained by treating wild-type cells with $N$-methyl$N^{\prime}$-nitro- $N$-nitrosoguanidine, were selected on fructose medium containing 1\% 2-deoxy-D-glucose. One mutant, designated $\mathbf{R}_{33}$, displayed a significantly decreased initial rate of uptake of D-glucose, 2-deoxy-D-glucose, Dgalactose and D-xylose, and was unable to accumulate the latter three sugars. However, the residual monosaccharide transport was still energy-dependent. The mutant displayed significantly altered transport parameters for D-glucose and D-xylose. These results are evidence for the isolation of a mutant defective in the glucose carrier.
\end{abstract}

\section{Introduction}

The obligatory aerobic yeast Rhodotorula glutinis is capable of transporting a wide variety of metabolizable and non-metabolizable monosaccharides by an electrogenic $\mathrm{H}^{+}$-symport (Höfer \& Misra, 1978; Hauer \& Höfer, 1978). Early results suggested that the uptake of monosaccharides was mediated by a common membrane transport system, displaying a high substrate specificity for D-glucose (Kotyk \& Höfer, 1965; Höfer \& Kotyk, 1968; Höfer, 1970; Höfer \& Dahle, 1972). Later results showing different relationships between transport velocity and $\mathrm{pH}$ with various substrates, as well as the lack of competition for transport in certain cases, indicated that D-fructose may be taken up by a different transport system from that for D-glucose (Janda et al., 1976; Höfer \& Dahle, 1972). D-Glucose seems to have a special position in monosaccharide transport. Its uptake is relatively independent of $\mathrm{pH}$, and it effectively blocks other transport systems, although it does not use all of them for its own uptake. Hence, we attempted to isolate glucose-transport-defective mutants, by using chemical mutagenesis and selecting for resistance to 2-deoxy-Dglucose (2-DG) during growth on a synthetic $D$-fructose medium. 2-DG-resistant mutants often lack sugarphosphorylating activities (Megnet, 1965; Maitra, 1970; Mahlberg et al., 1985). To distinguish between sugarphosphorylating deficiency and transport deficiency of the selected 2-DG-resistant mutants, a special screening

Abbreviation: 2DG, 2-deoxy-D-glucose. system has been developed. The results presented show that the mutant $\mathbf{R}_{33}$ exhibits a distinct defect of the glucose transport system, whereas its growth on Dfructose $+2-\mathrm{DG}$ was comparable with that of the wildtype strain without 2-DG.

\section{Methods}

Organism and growth. The collection strain used, Rhodotorula glutinis ATCC 26194 (CBS 6681) (taxonomically Rhodosporidium toruloides Banno, mating type a), was cultured in a synthetic medium with $2.5 \%$ (w/v) D-glucose as described by Kotyk \& Höfer (1965). For mutant selection the medium contained, instead of D-glucose, $2.5 \%(\mathrm{w} / \mathrm{v}) \mathrm{D}$ fructose and $1 \%$ (w/v) 2-deoxy-D-glucose (2-DG). For solid media $2.5 \%$ $(\mathrm{w} / \mathrm{v})$ agar was added. The screening plates contained $2.5 \% \mathrm{D}$-glucose or $2 \% \mathrm{D}$-galactose or $2 \% \mathrm{D}$-xylose as carbon source. The $\mathrm{pH}$ of all media was adjusted to 5.4 by adding $\mathrm{HCl}$. For transport experiments, wildtype cells and mutants were cultivated in liquid media on a gyratory shaker at $30^{\circ} \mathrm{C}$ for 24 and $26 \mathrm{~h}$ respectively. The cells were harvested by centrifugation, washed twice with distilled water, and aerated for $4 \mathrm{~h}$ as a $5 \%$ aqueous suspension (wet wt/vol.).

Isolation of mutants. Mutagenesis was performed by a modification of the method described by Mahlberg et al. (1985). A $1 \%$ aqueous wildtype cell suspension (wet wt/vol.) was aerated for 20 to $24 \mathrm{~h}$, then diluted to $0 \cdot 1,0.2$ and $0.5 \%$ and treated for $1 \mathrm{~h}$ at $30{ }^{\circ} \mathrm{C}$ with $0 \cdot 17,1.4$ and $1.7 \mathrm{~mm}-N$-methyl- $N^{\prime}$-nitro- $N$-nitrosoguanidine, respectively. The cells were washed three times with distilled water and cultured in liquid selection medium. After $10 \mathrm{~d}$ growth on a gyratory shaker at $30^{\circ} \mathrm{C}$, the cells were plated on agar plates of the same composition. The 2-DGresistant colonies (numbering 10823) were further tested for a potential transport defect phenotype by replica plating on the screening plates.

Transport experiments. The uptake and accumulation of $\left.\mathrm{D}-{ }^{14} \mathrm{C}\right] \mathrm{xy}-$ lose and 2-deoxy-D- $\left[{ }^{3} \mathrm{H}\right]$ glucose were measured by analysing hot-water cell extracts as described by Niemietz et al. (1981). The uptake of 
Table 1. Growth of 2-DG resistant mutants on the screening plates

2-DG-resistant mutants were patched on D-fructose-containing plates (for media and sugar content see Methods) and incubated at $30^{\circ} \mathrm{C}$. After $48 \mathrm{~h}$ the colonies were replica plated on plates containing D-xylose $(\mathrm{Xyl}), \mathrm{D}-$ galactose (Gal), D-glucose (Glc), 2-DG + D-fructose (2-DG + Fru) or Dfructose (Fru). The phenotypes of the 15 mutants potentially transport deficient after $48 \mathrm{~h}$ growth are presented: ++++ decreasing to indicate very good growth to no growth on the screening plates. The glucokinase negative mutant ( $\mathrm{Glk}^{-}$) was isolated by Mahlberg et al. (1985).

\begin{tabular}{llllll}
\hline \hline & \multicolumn{5}{c}{ Phenotype on agar plates } \\
\cline { 2 - 6 } & & \multicolumn{5}{c}{ G-DG } \\
Strain & Xyl & Gal & Glc & + Fru & Fru \\
\hline $\mathbf{R}_{35}$ & - & - & +++ & +++ & +++ \\
$\mathbf{R}_{\mathbf{2}}$ & - & - & ++ & ++ & ++ \\
$\mathbf{R}_{\mathbf{4}}$ & + & + & ++ & +++ & +++ \\
$\mathbf{R}_{\mathbf{4}}$ & + & + & +++ & +++ & ++++ \\
$\mathbf{R}_{52,54}$ & + & + & ++ & +++ & +++ \\
$\mathbf{R}_{53}$ & + & - & ++ & ++ & +++ \\
$\mathbf{R}_{56,47}$ & + & + & + & +++ & +++ \\
$\mathbf{R}_{1}$ & + & - & ++ & +++ & +++ \\
$\mathbf{R}_{\mathbf{8 5}}$ & - & - & ++ & ++ & ++ \\
$\mathbf{R}_{101}$ & - & - & ++ & +++ & ++ \\
$\mathbf{R}_{105}$ & - & + & + & +++ & ++++ \\
$\mathbf{R}_{106}$ & + & - & +++ & +++ & ++++ \\
$\mathbf{R}_{33}$ & - & - & ++ & +++ & +++ \\
Glk & +++ & + & ++ & +++ & ++++ \\
Wild-type & +++ & + & ++++ & - & ++++ \\
\hline \hline
\end{tabular}

$\mathrm{D}-\left[{ }^{14} \mathrm{C}\right]$ glucose, $\mathrm{D}-\left[{ }^{14} \mathrm{C}\right]$ galactose and $\mathrm{D}-\left[{ }^{14} \mathrm{C}\right]$ fructose was measured by determining the sugar concentration in the medium after centrifugation of $1 \mathrm{ml}$ samples taken from the reaction suspension at intervals. The radioactivity of $200 \mu \mathrm{l}$ of the supernatants in $4 \mathrm{ml}$ of scintillation cocktail was counted in a Packard Tricarb scintillation counter (model $\mathrm{He} / 18 / 1980$ ). The reaction suspension, incubated at $30^{\circ} \mathrm{C}$, consisted of $2.5 \%$ (wet wt/vol.) cells in $0.15 \mathrm{M}-\mathrm{KH}_{2} \mathrm{PO}_{4}$ buffer, $\mathrm{pH} 4.5$. Transport was started by the addition of the particular sugar at its chosen concentration. All experiments were repeated three to five times; error bars on graphs indicate SEM. Measurements of transport under anaerobic conditions were carried out as described by Höfer \& Nassar (1987).

Chemicals. 2-Deoxy-D-glucose was from Calbiochem; $N$-methyl- $N^{\prime}-$ nitro- $N$-nitrosoguanidine was purchased from Boehringer. The radiolabelled monosaccharides were from Amersham-Buchler. All other compounds were of reagent grade, from Merck.

\section{Results and Discussion}

\section{Development of media to screen for transport-deficient mutants}

In $R$. glutinis 2-DG is transported by the 'glucose carrier' (Taghikhani et al., 1984) but is toxic for cells when phosphorylated and incorporated as D-mannose analogues into the cell wall (Lehle \& Schwarz, 1976; Frankas et al., 1979). Resistance to 2-DG could be conferred upon mutants in either the uptake or the phosphorylating step. Earlier attempts to obtain glucose-transport-deficient mutants from $R$. glutinis in this laboratory resulted in the isolation of a glucokinase-negative mutant (Mahlberg et al., 1985). To exclude mutants with phosphorylating deficiency during the screening procedure, the population of cells grown following the mutagenic treatment was replica plated on agar plates containing three different sugars: D-glucose $(2.5 \%)$, D-galactose $(2 \%)$ and D-xylose $(2 \%)$. All three monosaccharides are taken up in $R$. glutinis via the same carrier system; however, each is phosphorylated by a different phosphokinase (Höfer, 1968; Janda et al., 1976). The monosaccharide concentrations used for screening were those which gave the most stable mutant phenotypes on agar plates.

Following mutagenesis and selection, as described in Methods, 15 out of 10823 mutants showed a potential transport-defective phenotype, as manifested by their decreased rate of growth on D-glucose, D-galactose and Dxylose (Table 1). These mutants were chosen for further biochemical characterization.

\section{Biochemical characterization of the mutants}

The transport properties of the mutants were analysed first. All mutants showed a significantly decreased initial rate of uptake of D-glucose, 2-DG, D-galactose and Dxylose, as compared with wild-type cells. Fig. 1 illustrates the decreased initial rate of D-glucose uptake in one of the mutants, designated $R_{33}$. Mutant $R_{33}$ was also unable to accumulate sugars, as shown for D-xylose in Fig. 2. The same results were obtained with D-galactose 


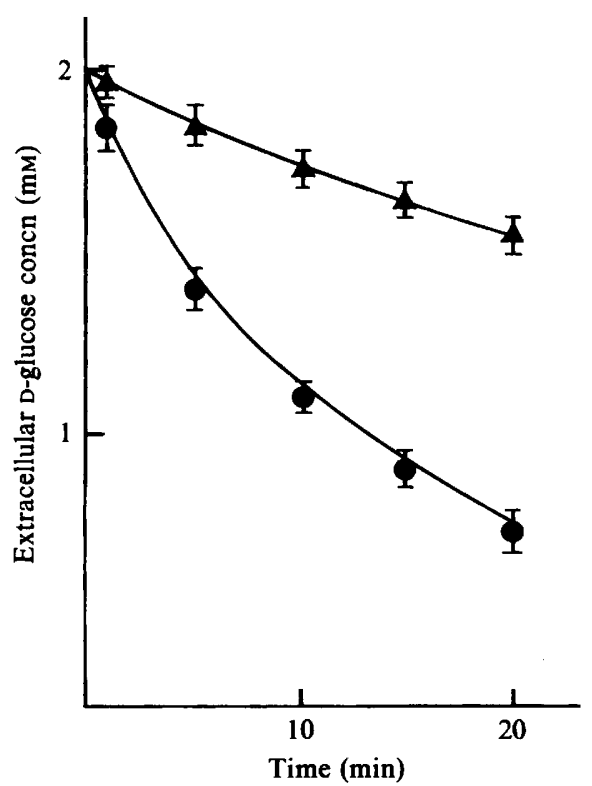

Fig. 1. Uptake of D-glucose into wild-type ( $)$ and mutant $R_{33}(\boldsymbol{A})$ cells, measured as consumption from the external medium. After starting the experiments (initial concentration $2 \mathrm{mM}$-D-glucose), samples were withdrawn at intervals and treated as described in Methods. Error bars represent SEM.

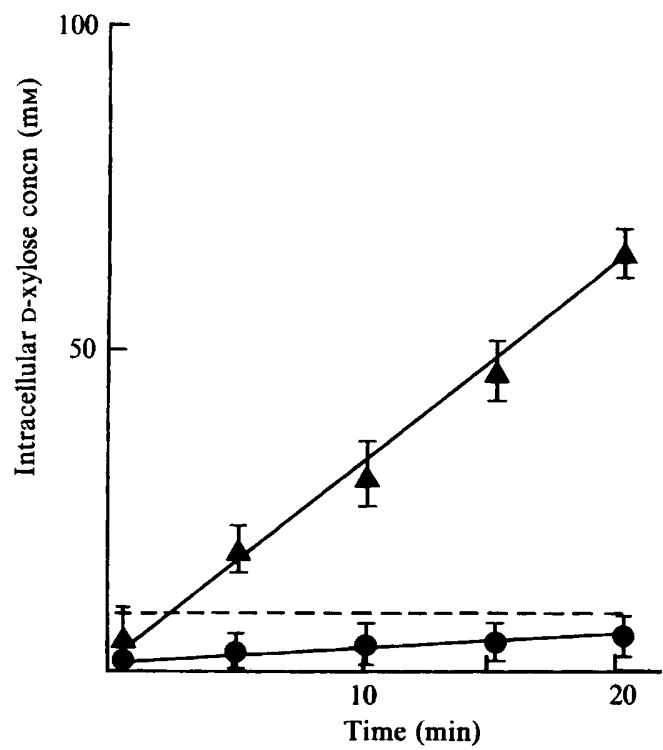

Fig. 2. Uptake and accumulation of D-xylose into wild-type (A) and mutant $R_{33}(O)$ cells. After starting the experiment (initial concentration $10 \mathrm{mM}$-D-xylose), samples of $1 \mathrm{ml}$ were withdrawn at intervals and treated as described in Methods. The broken line corresponds to the diffusion equilibrium. Error bars represent SEM.

and 2-DG as substrate (data not shown). Since the capacity for intracellular sugar accumulation is a characteristic property of the glucose carrier in wild-type cells, (Kotyk \& Höfer, 1965) the mutant $R_{33}$ was chosen for further studies.

$\mathbf{R}_{33}$ exhibited significantly altered transport parameters for D-glucose and D-xylose (Table 2). The halfsaturation constant $K_{\mathrm{T}}$, a measure of the effective
Table 2. Half-saturation constant $\left(K_{\mathrm{T}}\right)$ and maximal uptake velocity $\left(V_{\mathrm{T}}\right)$ for glucose and xylose in the wild-type strain (WT) and mutant $R_{33}$

Cell suspensions (about $4 \mathrm{mg}$ dry wt $\mathrm{ml}^{-1}$ ) were incubated in $0 \cdot 15 \mathrm{M}^{-} \mathrm{KH}_{2} \mathrm{PO}_{4}$ buffer, $\mathrm{pH} 4 \cdot 5$, at $30^{\circ} \mathrm{C}$. The kinetic parameters were estimated from double reciprocal plots. The results are the mean of four measurements; SEM averaged $\pm 3 \%$ of the mean.

\begin{tabular}{llcc}
\hline \hline & & & \\
Monosaccharide & Strain & $\begin{array}{c}K_{\mathrm{T}} \\
(\mathrm{mM})\end{array}$ & $\begin{array}{c}V_{\mathrm{T}} \\
\text { [nmol (mg dry wt) } \\
\text { min }^{-1} \text { ] }\end{array}$ \\
\hline D-Glucose & $\mathrm{WT}^{*}$ & 0.04 & 21 \\
D-Xylose & $\mathrm{R}_{33}$ & 4 & $2 \cdot 8$ \\
& $\mathrm{WT}^{*}$ & 2 & 25 \\
& $\mathrm{R}_{33}$ & 40 & 2 \\
\hline
\end{tabular}

* Data taken from Klöppel \& Höfer (1976), recently verified for this paperpaper.

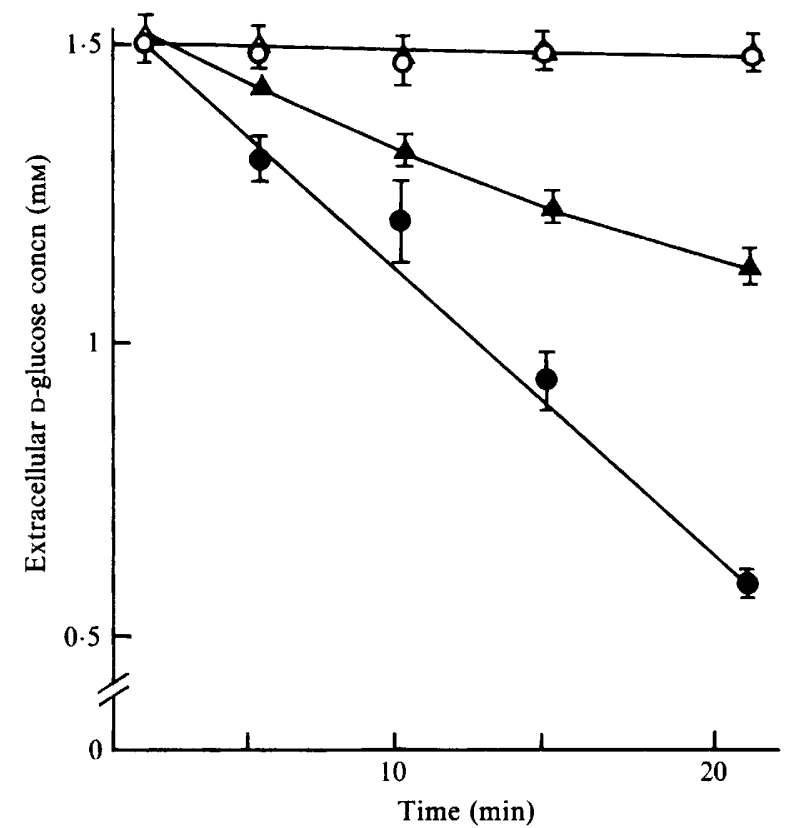

Fig. 3. Transport of D-glucose under anaerobic conditions into wildtype $(O)$ and mutant $R_{33}(\triangle)$ cells. The experiments were started by the addition of $1.5 \mathrm{~mm}-\mathrm{D}$-glucose. Anaerobic conditions were introduced by blowing purified nitrogen into a closed cuvette. Aerobic wild-type (O) and mutant $R_{33}(\boldsymbol{A})$ cells were used as controls. Error bars represent SEM.

affinity of the transport system for its substrate, was 100 fold higher for D-glucose, and 20-fold higher for D-xylose, in the mutant as compared with wild-type cells. The maximal velocity $V_{\mathrm{T}}$ of D-glucose and D-xylose uptake in the mutant was also about 10 -fold lower than that in wild-type cells. Thus, mutant $\mathbf{R}_{33}$ was affected both in the substrate binding and in the translocation step of the glucose transport cycle. The transport parameters for fructose are not presented, since fructose uptake decreased rapidly during cell aeration (by $95 \%$ in $1 \mathrm{~h}$ ). Even 


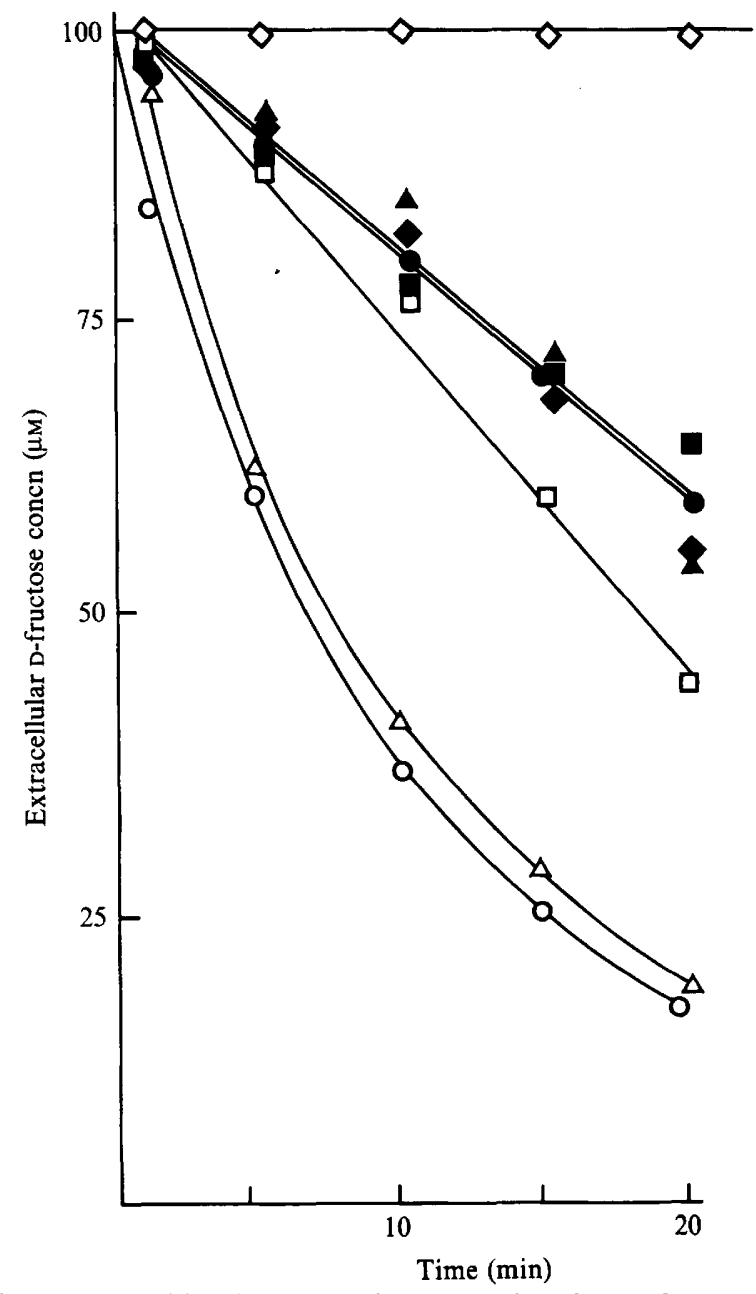

Fig. 4. Competition between D-fructose and D-glucose for entry in $R$. glutinis cells. Uptake of $0.1 \mathrm{mM}-\mathrm{D}$-fructose, measured as substrate consumption from the external medium, into wild-type (open symbols) and mutant $R_{33}$ (filled symbols) cells. D-Glucose concentrations : $0 \mathrm{mM}$ $(\mathrm{O}, \bullet) ; 0 \cdot 1 \mathrm{mM}(\triangle, \Delta) ; 1 \mathrm{~mm}(\square, \square) ; 4 \mathrm{~mm}(\diamond, \diamond)$.

during the harvesting period $(15-20 \mathrm{~min})$, the rate of fructose uptake diminished by one-third to one-half of the maximal value (unpublished results).

To test whether or not the altered properties of mutant $\mathbf{R}_{33}$ were due to a defect in its energy coupling, the uptake of $D$-glucose into $R_{33}$ cells under anaerobic conditions was examined. The method used was chosen because anaerobic conditions in the obligatorily aerobic yeast $R$. glutinis have the same effect as addition of metabolic inhibitors or uncouplers, without having any side-effect on cellular membranes (Höfer \& Kotyk, 1968; Höfer, 1971). The reduced uptake of D-glucose into $R_{33}$ cells was still inhibited under anaerobic conditions, indicating that uptake was tightly coupled to metabolic energy (Fig. 3). Since D-fructose uptake showed the same energy dependence as D-glucose (data not shown), a defect in the energy coupling of transport in the mutant appeared unlikely.
The present results are interpreted as evidence for the isolation of a mutant impaired in the glucose carrier. Even if the mutagenesis did not result in a loss of the glucose carrier, the special role of D-glucose in monosaccharide transport (Höfer \& Dahle, 1972; Janda et al., 1976) was affected. Competition experiments between Dfructose and increasing concentrations of D-glucose were carried out (Fig. 4). Whereas higher concentrations of Dglucose strongly inhibited D-fructose transport in wildtype cells, D-glucose had no effect on D-fructose uptake in the mutant $R_{33}$ cells.

The results of competition experiments, as well as the fact that $R_{33}$ was isolated using $D$-fructose as the carbon source for selection, have laid the way for investigation of a cryptic fructose transport system. Mutant $R_{33}$ will be a useful tool for examination of cryptic transport systems and for obtaining evidence of the existence of more monosaccharide transport systems in the plasma membrane of $R$. glutinis.

This work was supported by the Deutsche Forschungsgemeinschaft (grant no. Ho 555/12).

\section{References}

FrANKAS, V., SVOBODA, A. \& BAUER, S. (1979). Inhibitory effect of 2deoxy-D-glucose on the formation of the cell wall in yeast protoplasts. Journal of Bacteriology 98, 744-748.

HAUER, R. \& HöFER, M. (1978). Evidence for interactions between the energy-dependent transport of sugars and the membrane potential in the yeast Rhodotorula gracilis (Rhodosporidium toruloides). Journal of Membrane Biology 43, 335-349.

HöFER, M. (1968). Estimation of pathways of glucose catabolism in Rhodotorula gracilis. Folio Microbiologica 13, 373-378.

HöFER, M. (1970). Mobile membrane carrier for monosaccharide transport in Rhodotorula gracilis. Journal of Membrane Biology 3, 7382.

HÖFER, M. (1971). Transport of monosaccharides in Rhodotorula gracilis in the absence of metabolic energy. Archiv für Mikrobiologie $80,50-61$.

HöfER, M. \& DAHLE, P. (1972). Glucose repression of inducible enzyme synthesis in the yeast Rhodotorula gracilis: effect of the cell membrane transport. European Journal of Biochemistry 29, 326-332.

HöFER, M. \& KoTYK, A. (1968). Tight, coupling of monosaccharide transport and metabolism in Rhodotorula gracilis. Folia Microbiologica 13, 197-204.

HÖFER, M. \& MISRA, P. C. (1978). Evidence for a proton/sugar symport in the yeast Rhodotorula gracilis (glutinis). Biochemical Journal 172, $15-22$.

HöFER, M. \& NASSAR, F. R. (1987). Aerobic and anaerobic uptake of sugars in Schizosaccharomyces pombe. Journal of General Microbiology 133, 2163-2172.

JANDA, S., KotYK, A. \& TAuchova, R. (1976). Monosaccharide transport systems in the yeast Rhodotorula glutinis. Archives of Microbiology 111, 151-154.

KLÖPPEL, R. \& HöFER, M. (1976). Transport und Umsatz von Polyalkoholen bei der Hefe Rhodotorula gracilis (glutinis). I. Konstitutiver Polyalkoholtransport. Archives of Microbiology 107, 329-334.

KOTYK, A. \& HöFER, M. (1965). Uphill transport of sugars in the yeast Rhodotorula gracilis. Biochimica et Biophysica Acta 102, 410-422. 
LEHLE, L. \& SchwARZ, R. T. (1976). Formation of dolichol monophosphate 2-deoxy-D-glucose and its interference with glycosylation of mannoproteins in yeast. European Journal of Biochemistry 67, 239-245.

MAHLBERG, D., HöFER, M. \& TÄUBER, A. (1985). Sugar transport and hexose-ATP-kinase activity in a 2-deoxy-D-glucose tolerant mutant of the yeast Rhodotorula glutinis. Journal of General Microbiology 131, 479-485.

MaITRA, P. K. (1970). A glucokinase from Saccharomyces cerevisiae. Journal of Biological Chemistry 245, 2423-2431.
MEGNET, R. (1965). Effect of 2-deoxyglucose on Schizosaccharomyces pombe. Journal of Bacteriology 90, 1032-1035.

Niemietz, C., HAUER, R. \& HöFER, M. (1981). Active transport of charged substrates by a proton/sugar cotransport system. Biochemical Journal 194, 433-441.

Taghikani, M., Lavi, L. W., Woost, P. G. \& Griffin, C. C. (1984).

Kinetics of D-glucose and 2-deoxy-D-glucose transport in Rhotorula glutinis. Biochimica et Biophysica Acta 803, 271-278. 